\title{
Contribuições da atividade leiteira para o desenvolvimento rural e para a reprodução da agricultura familiar em um município do sul catarinense ${ }^{1}$
}

\author{
Contribution of milk activity to rural development and reproduction of family \\ farming in a municipality in southern Santa Catarina \\ Contribuciones de la actividad lechera para el desarrollo rural y para la \\ reproducción de la agricultura familiar en un municipio del sur catarinense
}

\author{
Vandreça Vigarani Dorregão \\ Giovana Ilka Jacinto Salvaro ${ }^{3}$ \\ Dimas de Oliveira Estevam²
}

\begin{abstract}
Resumo: Como parte das discussões apresentadas em uma dissertação, desenvolvida no período de 20162018, o artigo buscou demonstrar as contribuições da atividade leiteira para o desenvolvimento rural e para a reprodução da agricultura familiar em um município do sul catarinense. Os resultados analisados evidenciaram a relevância da atividade leiteira na região, assim como mudanças significativas nas unidades familiares de produção pesquisadas.
\end{abstract}

Palavras-chave: agricultura familiar; desenvolvimento rural; atividade leiteira.

Abstract: As part of the discussions presented in a dissertation, developed in the period 2016-2018, the article sought to demonstrate the contributions of milk activity to rural development and to the reproduction of family agriculture in a municipality in southern Santa Catarina. The results analyzed evidenced the relevance of milk activityin in the region, as well as significant changes in the production family units surveyed.

Keywords: family agriculture; rural development; milk activity.

Resumen: Como parte de las discusiones presentadas en una disertación, desarrollada en el período 20162018, el artículo buscó demostrar las contribuciones de la actividad lechera para el desarrollo rural y para la reproducción de la agricultura familiar en un municipio del sur catarinense. Los resultados analizados evidenciaron la relevancia de la actividad lechera en la región, así como los cambios significativos en las unidades familiares de producción encuestadas.

Palabras clave: agricultura familiar; desarrollo rural; actividad lechera.

\section{INTRODUÇÃO}

Este artigo é parte das discussões apresentadas na dissertação de mestrado da primeira autora, desenvolvida no período de 2016-2018, que teve como objetivo geral analisar a participação de mulheres na atividade leiteira no município de Orleans, SC. Nesse sentido, no presente artigo, por meio da seleção de um conjunto específico de informações, objetiva-se demonstrar as contribuições da atividade leiteira para o desenvolvimento rural e para a reprodução da agricultura familiar no município ${ }^{4}$.

Para a elaboração da dissertação, ao longo do percurso investigativo, foram realizadas pesquisas documentais em órgãos e setores como Instituto Brasileiro de Geografia e Estatísticas

\footnotetext{
${ }^{1}$ O presente trabalho foi realizado com apoio da Coordenação de Aperfeiçoamento de Pessoal de Nível SuperiorBrasil (CAPES) - Código de Financiamento 001.

${ }^{2}$ Centro Universitário Barriga Verde (Unibave), Orleans, Santa Catarina, Brasil.

${ }^{3}$ Universidade do Extremo Sul Catarinense (UNESC), Criciúma, Santa Catarina, Brasil.

${ }^{4}$ Ressalta-se que as questões de gênero e relacionadas à divisão sexual do trabalho na atividade leiteira, tratadas na pesquisa originária, pelos limites do próprio artigo, não se configuram como foco de debate.
} 
(IBGE), Empresa de Pesquisa Agropecuária e Extensão Rural de Santa Catarina (EPAGRI), Secretaria do Estado de Agricultura de Santa Catarina, entre outros. Além disso, considerando o objetivo geral da pesquisa, no ano de 2017, foram realizadas entrevistas com dez mulheres agricultoras familiares que realizam a atividade leiteira no município de Orleans e residem em comunidades rurais que se destacam na atividade em foco. O critério de seleção utilizado foi o de acessibilidade (GIL, 2010), considerando o contato prévio da pesquisadora com o campo de pesquisa e a presença significativa da produção leiteira; foram entrevistadas as mulheres das comunidades de Brusque do Sul (uma entrevistada), Morro da Palha (três entrevistadas), Barracão (uma entrevistada), Rio Laranjeiras (duas entrevistadas), Boa Vista (uma entrevistada), Chapadão (uma entrevistada) e Curral Falso (uma entrevistada). Mediante a autorização das mulheres, as entrevistas foram gravadas em áudio e transcritas na íntegra. A abordagem foi de natureza qualitativa, a partir do que propõe González Rey (2005), na e pela construção de indicadores que adquirem significado a partir da interpretação do/a pesquisador/a, o que possibilita elaborar categorias analíticas específicas. As informações reunidas por meio da pesquisa documental, em grande medida, foram analisadas a partir de uma estatística descritiva em diálogo com a abordagem teórico conceitual e interdisciplinar previamente selecionada.

Além do primeiro tópico relativo às considerações iniciais, o conteúdo do artigo está organizado em três tópicos. No segundo tópico, são reunidos alguns apontamentos sobre o desenvolvimento rural, a agricultura familiar e a atividade leiteira. Posteriormente, no terceiro tópico, denominado resultados e discussão, os conteúdos foram organizados em três categorias específicas: caracterização das famílias e das unidades familiares de produção pesquisadas; a representatividade da atividade leiteira no conjunto das atividades desenvolvidas nas unidades familiares de produção; o processo de comercialização da produção leiteira- dificuldades e avanços na perspectiva das entrevistadas. O último tópico trata das considerações finais.

\section{DESENVOLVIMENTO RURAL, AGRICULTURA FAMILIAR E ATIVIDADE LEITEIRA: ALGUNS APONTAMENTOS}

Para o alcance do objetivo proposto no texto, no âmbito teórico conceitual, argumenta-se a exposição de alguns apontamentos sobre desenvolvimento rural, agricultura familiar e atividade leiteira, o que implica, em um primeiro momento, retomar a própria concepção de desenvolvimento que orienta o processo investigativo. A literatura selecionada e mobilizada ao longo na pesquisa, de forma consensual, evidencia certa compreensão de desenvolvimento e de desenvolvimento socioeconômico que não se limita à medida de um conjunto de indicadores de crescimento. Como representativo de tal perspectiva, faz-se referência ao entendimento de Sen (2000), apresentado na obra intitulada "Desenvolvimento como Liberdade", acerca do processo de desenvolvimento, que só acontece mediante a expansão de liberdades reais possíveis de serem desfrutadas pelas pessoas. Para o autor, além dos avanços tecnológicos, da modernização e da industrialização, a liberdade depende das disposições sociais e econômicas, direitos civis, dentre outros aspectos dos quais o ser humano depende para seu pleno desenvolvimento.

Logo, o desenvolvimento requer que se removam as principais fontes de privação de liberdade: pobreza, tirania, carência de oportunidades econômicas e destituição social sistemática, negligência dos serviços públicos e intolerância ou interferência excessiva de Estados repressivos. "A violação da liberdade resulta diretamente de uma negação de liberdades políticas e civis por 
regimes autoritários e de restrições impostas à liberdade de participação na vida [social,] política e econômica da comunidade" (SEN, 2000, p. 18).

Diante disso, a concepção de desenvolvimento perpassa pelas capacidades individuais do ser humano, que é capaz de contribuir diretamente nesse processo. Nessa perspectiva, cabe retomar o debate de Furtado (1980) sobre a concepção de desenvolvimento em dois sentidos distintos: o que se refere à evolução de um sistema social de produção, o qual se torna mais eficaz mediante o progresso das técnicas, e ao processo de acumulação; e o que se refere ao grau de satisfação das necessidades humanas. Portanto, "[...] a concepção de desenvolvimento de uma sociedade não é alheia a sua estrutura social [...]" (FURTADO, 1980, p. 16).

De acordo com o autor, o aumento da eficácia do sistema de produção não garante a melhor satisfação das necessidades elementares da população, pelo contrário, o que se observa é que, com a introdução de técnicas mais sofisticadas, o que se tem é a degradação das condições de vida de uma massa populacional. Com o avanço do processo de acumulação, parte da população não alcança o nível de renda real necessária para satisfazer o que considera necessidades elementares em decorrência de formas de consumo muito mais sofisticadas (FURTADO, 1980).

A reflexão acerca do desenvolvimento no período após a Segunda Guerra Mundial ocasionou a tomada de consciência quanto ao atraso econômico em que vive a maioria da humanidade, sendo constatado, a partir dos índices de mortalidade infantil, grau de alfabetização, enfermidades contagiosas, os quais amalgamaram as ideias a respeito do desenvolvimento, bem-estar social e modernização (FURTADO, 1980).

Observa-se a incapacidade do indivíduo de intervir nessa situação, estando como sujeito passivo, vivenciando as consequências, positivas e negativas, com oportunidades limitadas acerca de um processo histórico que o colocou em tal condição. Diante disso, vale destacar o que Sen (2000, p. 26) argumenta sobre a economia e o processo de desenvolvimento centrado na liberdade do indivíduo e na sua condição de agente, uma vez que "com oportunidades sociais adequadas, os indivíduos podem efetivamente moldar seu próprio destino e ajudar uns aos outros".

De acordo com Sen (2000), vive-se num mundo de opulência, com significativas mudanças que vão além da economia e, no registro temporal, o século XX foi marcado pela possibilidade estabelecida de um regime democrático e participativo como modelo de organização política. No entanto, conforme argumenta o mesmo autor, ainda se vive num mundo cerceado por privações, destituição e opressão, onde persistem problemas antigos juntamente com novos, a exemplo da pobreza, necessidades essenciais não satisfeitas, violação de liberdades, dentre outros aspectos que demarcam desigualdades e uma condição de privação dos direitos essenciais do ser humano.

Sendo assim, como parte de um mesmo processo, a superação dos problemas existentes é condição essencial para o processo de desenvolvimento, bem como a condição de agente dos indivíduos é primordial para que esse mesmo indivíduo possa lidar com as privações que lhe são postas na sociedade, mas é restrita pelas oportunidades sociais, políticas e econômicas de que dispomos (SEN, 2000).

As considerações apresentadas sobre desenvolvimento socioeconômico vêm ao encontro das compreensões de desenvolvimento rural e agricultura familiar que orientaram a pesquisa. Desse modo, como questões centrais para o debate, são apresentadas algumas considerações com base em autores/as que tematizam/problematizam o desenvolvimento rural e a agricultura familiar. Carneiro (2012) destaca que pesquisas têm apontado para mudanças no meio "rural" de uma forma que não foi prevista pela Sociologia Rural, pois o que havia era a compreensão 
de que estava estabelecida uma oposição entre campo e cidade, como realidades espaciais e sociais descontínuas, com ênfase na subordinação da primeira em relação à segunda, de modo que diferenças entre esses dois espaços tenderiam a desaparecer a partir de um processo de urbanização, tido como natural e inevitável (CARNEIRO, 2012).

Sob essa ótica, desenvolveu-se uma Sociologia Rural, que, segundo Martins (2001), tem um pesado débito com as populações rurais, uma vez que as gerações foram vitimadas por uma sociologia que se dedicou à inovação, em que a prioridade era a própria inovação, deixando aos filhos o débito social do desenraizamento e consequente migração para as cidades ou para as vilas pobres próximas das grandes fazendas de onde saíram, indo para lugares de poucas oportunidades e de nenhuma qualidade de vida. Aos poucos, observa-se que essas populações têm seus próprios códigos de conhecimento e sua própria concepção de destino e que são tão verdadeiros quanto os códigos e concepções de setores da sociedade dos quais os sociólogos se sentem mais a vontade em tratar (MARTINS, 2001).

Três principais correntes de pensamento acerca do mundo rural nas sociedades contemporâneas são apresentadas por Carneiro (2012), a saber: a primeira delas se refere ao fim do mundo rural em decorrência da diminuição da população agrícola em decorrência do modelo produtivista que está relacionado ao processo de urbanização das localidades rurais a partir da generalização do padrão de vida urbano, o que atestaria o fim do rural; a segunda perspectiva defende a permanência das diferenças espaciais e sociais, mantendo a dualidade campo-cidade, de modo a negar o fim do mundo rural e da dualidade que se estabelece em relação ao urbano, havendo uma aproximação entre os padrões de vida da população rural e urbana; a "[...] terceira corrente sustenta o fim da dicotomia rural-urbano para qualificar realidades sociais distintas nas sociedades contemporâneas" (CARNEIRO, 2012, p. 27).

Para Carneiro (2012), a novidade do rural contemporâneo está na possibilidade de combinações, nos mesmos espaços, de atividades consideradas do meio urbano, como o setor de serviços. Sendo assim, "a pluriatividade é uma noção que resulta das evidências sobre a inserção plural dos membros das famílias rurais no mercado de trabalho e sobre a diversificação dos usos dos espaços rurais." (CARNEIRO, 2012, p. 39). A partir desse viés, argumenta-se que a agricultura familiar ganha espaço e reconhecimento diante da sua importância para o desenvolvimento socioeconômico e rural, de um lugar, de uma cidade, de um país.

Wanderley (2009) faz uma reflexão a partir de alguns aspectos e hipóteses que contribuem para um melhor entendimento sobre determinada compreensão de agricultura familiar que fundamentou a pesquisa. Segundo a autora, a agricultura familiar é um conceito genérico que congrega situações específicas e particulares. A agricultura familiar moderna está inserida em um contexto socioeconômico que a obriga a se adaptar e realizar modificações na forma de produzir sua vida social tradicional, e, nesse sentido, "deve-se, portanto, considerar a capacidade de resistência e de adaptação dos agricultores aos novos contextos econômicos e sociais" (WANDERLEY, 2003, p. 48).

A agricultura familiar, de acordo com Wanderley (2001, p. 22), não é uma nova categoria analítica da sociedade rural, mas na atualidade, no Brasil, "assume ares de novidade e renovação." Segundo a autora, trata-se de uma agricultura familiar como um novo personagem, diferenciando-se do camponês tradicional, uma vez que "[...] a combinação entre propriedade e trabalho assume, no tempo e no espaço, uma grande diversidade de formas sociais" (WANDERLEY, 2001, p. 23). 
No Brasil, a agricultura familiar passa por um processo de (re)descobrimento, conforme destaca Schneider (2014). O autor contextualiza a formação e evolução da agricultura familiar no Brasil, fazendo uma apresentação dos principais dados e informações: a agricultura familiar no Brasil tem sua trajetória ligada ao processo de redemocratização do país, aliado ao processo de desenvolvimento, em que o Estado e as políticas públicas, após a constituição de 1988, tiveram um papel de extrema relevância no reconhecimento de demandas da sociedade (SCHNEIDER, 2014).

O reconhecimento da agricultura familiar no Brasil é recente e se deve a três fatores: a retomada do movimento sindical após o término da ditadura militar, a atuação dos mediadores e intelectuais com debates acerca do tema no início da década de 1990 e, por último, a atuação do Estado e suas políticas públicas, com consequente reconhecimento do setor especialmente a partir da criação do Programa Nacional de Fortalecimento da Agricultura Familiar (Pronaf) (SCHNEIDER, 2014).

A evolução desses fatores ao longo dos últimos 20 anos, segundo Schneider (2014), pode ser dividida em três fases. A primeira fase se refere ao (re)descobrimento da agricultura familiar no período de 1990 a 1995. Nesse período, há a afirmação política e acadêmica da categoria agricultura familiar, encontrando lugar tanto nos movimentos social e sindical quanto no acadêmico. Isso se deve ao fim da ditadura militar, o que possibilitou diversas mobilizações em prol do crédito, melhoria de preços, comercialização diferenciada e implementação da regulação referente à previdência social (SCHNEIDER, 2014). Aliado a esse contexto, destaca-se a mobilização dos movimentos sociais rurais que culminaram na criação do Pronaf no ano de 1996, com o decreto da Presidência, n. 1.946, 28/07/1996, e depois, cria-se a Lei da Agricultura Familiar, n. 11.326/2006 (SCHNEIDER, 2014).

Nessa fase, destacam-se também os estudos, publicações e pesquisas acerca da categoria agricultura familiar, realizadas por autores como Abramovay (1992), Veiga (1991), Lamarche (1993; 1994) e Schneider (2014). Na segunda fase, Schneider (2014) destaca a criação do PRONAF até a criação da Lei da Agricultura Familiar em 2006. Para o autor, é nesse espaço de tempo que a agricultura familiar vai se consolidar no âmbito político, "[...] tornando-se uma categoria social que atrai a maior parte dos programas e políticas de desenvolvimento rural" (SCHNEIDER, 2014, p. 27). Vale destacar que, em 2003, quando o Presidente Luiz Inácio Lula da Silva iniciou seu governo no Brasil, novos Programas foram criados visando ao estímulo da Agricultura Familiar, a exemplo do Fome Zero, o Programa de Aquisição de Alimentos e o Programa Nacional de Alimentação Escolar (SCHNEIDER, 2014). Mas, para Schneider (2014), a maior afirmação institucional, que obteve maior alcance para a agricultura familiar foi a aprovação da Lei da Agricultura Familiar Lei 11.326/2006 (BRASIL, 2006).

Art. 3 Para os efeitos desta Lei, considera-se agricultor familiar e empreendedor familiar rural aquele que pratica atividades no meio rural, atendendo, simultaneamente, aos seguintes requisitos:

I- não detenha, a qualquer título, área maior do que 4 (quatro) módulos fiscais;

II- utilize predominantemente mão-de-obra da própria família nas atividades econômicas do seu estabelecimento ou empreendimento;

III- tenha percentual mínimo da renda familiar originada de atividades econômicas do seu estabelecimento ou empreendimento, na forma definida pelo Poder Executivo; (Inciso com 
redação dada pela Lei no 12.512 , de 14/10/2011)

IV- dirija seu estabelecimento ou empreendimento com sua família. (BRASIL, 2006).

Na terceira fase, o debate sobre Agricultura Familiar trata do momento atual e, segundo Schneider (2014), esse momento estaria atrelado à divulgação do Caderno Especial do Censo Agropecuário de 2006, que ocorreu em 2009, trazendo dados importantes acerca da agricultura familiar. A partir desse fato, foi estabelecido o lugar da agricultura familiar e o seu papel para o desenvolvimento do rural no Brasil (SCHNEIDER, 2014).

Quanto à temática "agricultura familiar e atividade leiteira", os estudos de Mello (1998), Maraschin (2004), Santiago (2010), Moraes (2010), Rodrigues (2011), Schmitz (2014) e Luz (2014) trazem discussões acerca da evolução da atividade leiteira, das transformações dessa atividade produtiva, da participação da mulher na atividade, entre outras questões.

No que compreende alguns dados específicos sobre a produção leiteira no Sul Catarinense, a Pesquisa Pecuária Municipal (2010-2016) do IBGE (2015) demonstrou que a mesorregião ocupou o terceiro lugar no comparativo com as mesorregiões geográficas de Santa Catarina, no ano de 2016, alcançando uma produção total de 217.188 (mil litros). As mesorregiões do Oeste Catarinense e do Vale do Itajaí, respectivamente, ocuparam o primeiro e o segundo lugar, com uma produção de 2.367.477 (mil litros) e 262.463 (mil litros). Ainda, no Sul Catarinense, observa-se um crescimento significativo da produção leiteira do ano de 2012 em relação ao ano de 2013, de um total de 180.640 (mil litros) para 257.366 mil litros.

De acordo com a mesma fonte de dados, em uma delimitação territorial mais específica, na região da Associação dos Municípios da Região Carbonífera (AMREC) ${ }^{5}$, Orleans desponta como o município com maior produção de leite, ao longo dos anos, sendo que a produção dobrou de 2010 em relação ao ano de 2016, respectivamente, 7.928 (mil litros) e 15.330 (mil litros). Percebe-se um crescimento importante e que suscita reflexões quanto à relevância da atividade leiteira no Sul Catarinense, especialmente no município de Orleans, território da pesquisa, uma vez que é impulsionada, principalmente, por estabelecimentos agropecuários caracterizados como de agricultura familiar. De acordo com dados do Censo Agropecuário de 2006, Orleans possui 643 estabelecimentos agropecuários e destes, 609 são caracterizados como de agricultura familiar. Conforme o último Censo Agropecuário, o total da produção de leite de vaca, em Orleans, 91,8\% era proveniente de estabelecimentos agropecuários desta natureza (IBGE, 2006).

\section{RESULTADOS E DISCUSSÕES}

\subsection{Caracterização das famílias e das unidades familiares de produção pesquisadas}

De acordo com informações das mulheres entrevistadas (nove casadas e uma viúva, com idades entre 28 e 51 anos), em uma caracterização geral, ressalta-se que as famílias eram compostas por 2 a 5 integrantes, sendo que nove das entrevistadas tinham filhos(as); quatro delas tinham filhos(as) solteiros(as) que residiam no perímetro urbano do município de Orleans, SC, pois foram cursar o Ensino Superior e trabalhar. As famílias, na sua maioria, eram formadas pelo casal e pelos/as filhos/as. Em alguns casos, além do casal e os/as filhos/as, nas unidades familiares,

\footnotetext{
${ }^{5}$ A AMREC é formada por 12 municípios associados, a saber: Balneário Rincão, Cocal do Sul, Criciúma, Forquilhinha, Içara, Lauro Muller, Morro da Fumaça, Nova Veneza, Orleans, Siderópolis, Treviso e Urussanga. Disponível em: http://www.amrec.com.br/index/municipios-associados/codMapaltem/42512. Acesso em: 26 nov. 2016.
} 
residiam os avós. Cabe observar que o número reduzido de integrantes por família tem efeitos nas atividades desenvolvidas na unidade de produção e na reprodução da agricultura familiar, na medida em que não se dispõe de força de trabalho que possibilite a continuidade de algumas atividades, sobretudo, das que envolvem tarefas intensivas não mecanizadas, como no caso do cultivo do fumo, por exemplo.

As unidades familiares de produção pesquisadas possuíam uma dimensão entre 13,8 a 40 hectares, atendendo ao que estabelece a Lei da Agricultura Familiar (11.326, de 24 de julho de 2006), em seu Art. 3ㅇ, inciso I "não detenha, a qualquer título, área maior do que quatro módulos fiscais" (BRASIL, 2006). De acordo com o Instituto Nacional de Colonização e Reforma Agrária (INCRA, 2017) 6 , 4 módulos fiscais, no município de Orleans, Santa Catarina, correspondem à dimensão de 56 hectares.

Segundo as mulheres entrevistadas, em linhas gerais, as unidades familiares dispunham de casa residencial, chiqueiro, galinheiro, galpões, paióis, açudes, estufas elétricas, garagem para trator e implementos agrícolas, e todas as famílias possuíam carro ou moto ou apenas moto. Além disso, possuíam um ou dois tratores, acompanhados de implementos agrícolas, tais como: carreta, ensiladeira, subsolador, grade, rotativa, pulverizador, batedeira de grãos, espalhador de esterco, dentre outros implementos úteis à realização das atividades desenvolvidas nas propriedades.

Em relação aos equipamentos específicos para a realização da atividade leiteira, das mulheres entrevistadas, $80 \%$ responderam que, em suas propriedades, tinham ordenhas com o sistema canalizado para armazenamento e resfriamento do leite. O sistema canalizado dispõe de algumas vantagens, como rapidez no processo de ordenha, lavagem automática e filtragem do leite, além de favorecer o processo de higienização do leite, uma vez que o(a) agricultor(a) não tem contato direto com o produto, o qual é canalizado da ordenha direto para o resfriador. Uma das entrevistadas relatou acerca do processo de transição de ordenha balde ao pé para a ordenha canalizada:

O custo [risos] bem alto, mas melhorou a qualidade do leite, melhorou a mão de obra [...] reduziu a mão de obra e, com isso, a gente conseguiu até um preço melhor também. No começo a gente até tinha ordenha, mas usava o tarro, e era muito manual. Tinha que pegar os tarros pesados e colocar dentro do freezer. Agora já temos a canalizada, que aí facilitou muito né, não se coloca mais a mão no leite. O leite vai direto pro resfriador de 1000 litros. (E1, 2017).

Com a ampliação do setor industrial no setor lácteo e consequentemente a necessidade de mais matéria-prima para suprir essa indústria, houve a necessidade de as unidades de produção substituírem a produção realizada de forma rudimentar por algo mais tecnificado que garantisse a padronização da produção (SCHMITZ; SANTOS, 2013). As autoras destacam que é, nesse contexto, que surgem as normatizações referentes à qualidade do leite, normas de higiene, sanidade animal, dentre outros. Essa condição levou os(as) produtores(as) a investirem em melhorias na sua propriedade e, assim, adaptarem-se à nova realidade para realização da atividade leiteira.

\subsection{A representatividade da atividade leiteira no conjunto das atividades desenvolvidas nas unidades familiares de produção}

No conjunto das atividades produtivas desenvolvidas nas dez unidades familiares pesquisadas, a maior concentração de renda estava na atividade leiteira, conforme demonstrado pelas entrevistadas, na seguinte ordem: $50 \%$ atividade leiteira; $30 \%$ cultivo do fumo; $10 \%$ na atividade

\footnotetext{
${ }^{6}$ http://www.incra.gov.br/tamanho-propriedades-rurais
} 
leiteira e cultivo de fumo; $10 \%$ outras atividades. Os dados revelam a importância da atividade leiteira na composição da renda, o que contribui para o processo de manutenção e desenvolvimento das famílias e da região.

Ao longo da pesquisa, foi observada ainda certa predominância da produção de fumo em seis das dez unidades familiares pesquisadas. Três das entrevistadas informaram ter deixado de produzir o fumo, pelas dificuldades pertinentes ao tipo de cultivo, tais como intoxicação, falta de mão de obra e baixa valorização do produto no momento da venda às empresas. As demais entrevistadas, que cultivam o fumo, sinalizam que a família tem a intenção de não prosseguir com a produção, pelos mesmos motivos citados anteriormente.

Logo, a decisão de iniciar a atividade leiteira, segundo algumas das entrevistadas, apresentou-se como possibilidade de trabalhar com algo considerado menos "sofrido" do que a produção do fumo, uma vez que, do plantio até a sua colheita e a preparação para a venda às empresas integradas, a atividade demanda muito trabalho manual e contato com agrotóxicos. O adoecimento relacionado à produção de fumo no Brasil, conforme Riquinho e Hennington (2014), ainda é pouco documentado, mas estudos internacionais demonstram que a doença da folha verde, doenças respiratórias, intoxicação por agrotóxicos e acidente de trabalho são as principais formas de adoecimento.

Somando-se ao intento de findar o cultivo de fumo na unidade familiar pelos motivos descritos, algumas entrevistadas destacaram vantagens em iniciar com a atividade leiteira como o complemento da renda e/ou acesso a uma renda mensal, que, em outros cultivos ou atividades, não é possível. Sobre tal aspecto, três entrevistadas destacaram:

A vantagem, a vantagem do leite é o capital, a renda que entra mensal tu consegue te equilibrar durante o ano [...]. (E1, 2017).

Facilita, porque todo mês o dinheiro vem e no fumo é só uma vez por ano né. (E7, 2017).

A renda do leite junto com o fumo veio para complementar, porque ou a gente plantava muito fumo, e não fazia outra coisa e daí a gente não consegue porque é só em duas pessoas [...] até o pensamento é não plantar mais fumo, para ver em um ano o que vai acontecer. (E4, 2017).

Em algumas situações, a renda obtida pela venda do leite compensa as fragilidades de rendimento das outras atividades desenvolvidas na unidade familiar, como descrito por outra entrevistada: "[...] porque a gente tá pagando a maioria das coisas com o leite, tu vê que até adubo pro fumo a gente tá pagando com dinheiro do leite" (E10, 2017). Para a entrevistada E6 (2017), acontece o mesmo: "[...] entre outras coisas, ele [leite] tá cobrindo às vezes o que o outro não dá".

A viabilidade da atividade leiteira, de acordo com Ferrari et al. (2005), perpassa pelo campo financeiro, produtivo e social. Segundo os autores, essa atividade se torna importante para as famílias agricultoras no campo financeiro, por ser uma renda mensal e que pode contribuir para o equilíbrio das finanças da unidade familiar. A fácil adequação dos produtores e das unidades familiares às tecnologias necessárias para execução dessa atividade refere-se ao campo produtivo e, no campo social, como forma de superar as dificuldades diante da realização de outras atividades, que estejam em crise (FERRARI et al., 2005).

Quanto ao número total de vacas ordenhadas e a produção de leite nas unidades familiares, segundo informações das entrevistadas, foi possível identificar uma variação de 14 a 36 animais e 6000 a 16000 litros/mês, assim como a inexistência de um padrão. Por exemplo, uma 
propriedade com 23 vacas em produção apresentava a mesma quantidade de leite quando comparada a uma propriedade com 14 vacas, o que pode sugerir o levantamento de alguns questionamentos: as mulheres envolvidas na atividade leiteira conhecem os dados de produção de leite na sua unidade familiar, ou quem de fato detém esse conhecimento são seus esposos/ filhos? Além disso, verifica-se a necessidade que essas unidades de produção têm acerca de orientações, de trabalhos de extensionistas para tornar suas unidades de produção adequadas e produzindo adequadamente, conforme o tamanho do rebanho, a pastagem disponível, dentre outros aspectos que interferem na produção.

\subsection{0 processo de comercialização da produção leiteira: dificuldades e avanços na perspectiva das entrevistadas}

Apesar da constatação quanto à representatividade da atividade leiteira para a reprodução das unidades familiares e produção na agricultura familiar do munícipio estudado, as entrevistadas indicam dificuldades e avanços. Uma das dificuldades apontadas por algumas entrevistadas é com relação ao preço do leite. Conforme uma das mulheres entrevistadas:

É o preço. Pelo custo da alimentação que tem, deveria ser mais valorizada [...] Às vezes tu vê no mercado tá dois reais e trinta e cinco centavos [R\$2,35] e eles tão pagando um real e sessenta centavos [R\$1,60]. Chegou a um real e cinquenta e quatro centavos [R\$1,54], que foi o máximo que nós recebemos esse ano, quando estava aquela época lá que o leite parecia que estava valendo ouro. Mas aí a gente não entende o porquê, se tem o leite e tem o consumo, tem que ter a valorização de quem produz né?! (E4, 2017).

Nesse aspecto, vale destacar que algumas das unidades familiares pesquisadas estão se organizando em Cooperativas, como alternativa na busca por condições para continuarem com a atividade leiteira. Convém ressaltar que $40 \%$ unidades familiares pesquisadas já se inseriram no sistema de cooperativas para viabilizar a comercialização da sua produção. No entanto 60\% permanecem comercializando sua produção por via direta aos laticínios da região. Segundo Estevam et al. (2015, p. 02):

De um modo geral, estas cooperativas representam um mecanismo para viabilizar a inserção mais equilibrada dos agricultores familiares ao mercado, na medida em que permitem melhorar as condições socioeconômicas e de competitividade junto às agroindústrias, facilitam a compra de insumos e, sobretudo, as condições de negociação da comercialização. Os associados são responsáveis pela produção e participam de todo processo da tomada de decisão na etapa de comercialização.

Com isso, as cooperativas se apresentam como uma importante alternativa para viabilizar a produção resultante, não apenas da atividade leiteira, mas de outras atividades desenvolvidas nas unidades familiares. A partir de 2005, segundo Estevam et al. (2015), as cooperativas de leite foram sendo instituídas no Sul de Santa Catarina e, na ocasião do estudo realizado, existiam seis cooperativas em atividade e duas associações, com um total de 348 associados, os quais produzem um montante significativo de leite, em torno de um milhão e meio de litros.

Em Orleans, foi constituída, em 2014, a Cooperfale - Cooperativa de Agricultores Familiares e Produtores de Leite de Orleans. A Cooperativa atualmente possui 33 associados, e, no mês de dezembro, a produção de leite ultrapassou 150 mil litros (EPAGRI, 2018). As mulheres associadas da Cooperativa apontaram algumas vantagens em participar dessa forma de organização. Uma das entrevistadas era associada e participava também como secretária. Uma das entrevistadas 
se refere ao apoio do governo, por meio de projetos que resultem em incentivos aos associados da cooperativa:

Tem vantagem [...], que a gente consegue ganhar também um pouco do governo [...] no caso, eles ajudaram a fazer a fossa, o pasto, então tem bastante vantagem, na compra de ureia, essas coisas ajudam um pouco né [...]. (E6, 2017).

No caso das unidades familiares que vendem a produção de leite diretamente para o laticínio, o caminhão vem buscar o leite na propriedade, diariamente ou a cada dois ou três dias, conforme a produção da unidade familiar e capacidade de armazenamento do resfriador. Ao completar o mês, as unidades familiares recebem, por intermédio do motorista do caminhão, a nota com a quantidade de leite produzido/vendido, os valores descontados em virtude de alguma inconsistência apontada pelas análises do leite (feita periodicamente, por amostras de leite que são retiradas direto do resfriador) e o cheque com o valor pago pela produção daquele mês. Ou seja, o(a) produtor(a) não tem conhecimento antecipado do valor que será pago pelo seu produto.

Assim, as dificuldades para gestão e comercialização da sua produção, ficaram evidentes durante as entrevistas. As mulheres entrevistadas relataram o seu pouco ou total desconhecimento acerca do preço do leite, por exemplo. Nesse aspecto, a comercialização por intermédio da cooperativa trouxe alguns diferenciais, de acordo com uma das entrevistadas.

A gente tem uma pessoa que participa pela cooperativa de um fórum, o fórum de Cooperativas de Leite da Região Sul de Santa Catarina. Dentro desse fórum tem oito cooperativas se não me engano, duas associações e nós temos uma pessoa que participa das reuniões do CONSELEITE [...] reuniões onde vai a indústria, vai comércio, vai produtor, entende? Vão pra negociar o leite, mercado, preço, custo e aí eles tem uma base [...] então nós temos um representante do fórum que vai nessas reuniões e traz notícia [...]. (E1, 2017).

O relato demonstra um importante avanço em relação às ferramentas de gestão para o processo de negociação e venda do produto, além de dar maior segurança aos produtores. A entrevistada E3 sinalizou sua satisfação, ao mencionar a organização dos associados por redes sociais, como o WhatsApp, que possibilita e facilita a comunicação entre eles e a segurança das informações obtidas por meio da cooperativa.

\section{CONSIDERAÇÕES FINAIS}

Ao tratar do desenvolvimento socioeconômico de uma região, precisa-se ir além do aspecto econômico. De igual modo, é preciso considerar as condições de vida, de saúde, de bem-estar das pessoas do lugar. No município estudado, modificações vêm acontecendo, de forma a proporcionar melhores condições de sobrevivência aos que ali residem. Nesse sentido, a inserção da atividade leiteira nas unidades de agricultores familiares na região tem contribuído para esse processo. Atividades mais desgastantes, sofridas, como o cultivo do fumo, por exemplo, têm sido abandonadas ou diminuídas em busca de melhores condições de trabalho e de vida das famílias. Com isso, o estudo realizado demonstrou que a agricultura familiar no município foi sendo reestruturada e fortalecida a partir da atividade leiteira como atividade comercial nas unidades analisadas.

A possibilidade de se reinventar, a partir das condições do próprio território e das próprias famílias, é o que possibilita à agricultura familiar condições de reprodução. Com isso, condições de enfrentar as demandas impostas pelos próprios governos, que ora incentivam e ora suspendem políticas e ações para fortalecimento da agricultura familiar. Como demonstrado ao longo do 
texto, ressalta-se a importância de políticas públicas que tenham como foco o desenvolvimento e o fortalecimento da agricultura familiar no país, a exemplo do Pronaf, Juro Zero e Mais Alimentos.

Destaca-se que a realização da atividade leiteira na unidade familiar é transformada, passando de um método manual, mais rudimentar, de pequena produção, para um processo mecanizado, tal como a utilização da ordenha mecânica. As modificações no processo de produção e de gestão da atividade possibilitaram a comercialização do leite, dentro das exigências estabelecidas para tal. Enfim, espera-se que as unidades familiares possam seguir se fortalecendo e se reinventando a cada dia.

\section{REFERÊNCIAS}

ABRAMOVAY, Ricardo. Paradigmas do capitalismo agrário em questão. São Paulo: Hucitec/Edunicamp/ Anpocs, 1992.

BRASIL. Lei n. 11.326, de 24 de julho de 2006. Estabelece as diretrizes para a formulação da Política Nacional da Agricultura Familiar e Empreendimentos Familiares Rurais. Disponível em: http://www.planalto.gov. br/ccivil_03/_Ato2004-2006/2006/Lei/L11326.htm. Acesso em: 12 abr. 2017.

CARNEIRO, Maria José. Do rural como categoria de pensamento e como categoria analítica. In: CARNEIRO, Maria José (Coord.). Ruralidades contemporâneas: modos de viver e pensar o rural na sociedade brasileira. Rio de Janeiro: Mauad X/FAPERJ, 2012.

EMPRESA DE PESQUISA AGROPECUÁRIA E EXTENSÃO RURAL DE SANTA CATARIANA (EPAGRI). 2018. Disponível em: https://www.epagri.sc.gov.br/. Acesso em: 16 jan. 2018.

ESTEVAM, Dimas de Oliveira; MARIA, Fernanda Lidório; SALVARO, Giovana Ilka Jacinto. As estratégias coletivas dos/as agricultores/as familiares para acessar o mercado: estudo das cooperativas de leite do Sul de Santa Catarina - Brasil. In: CONGRESO LATINOAMERICANO DE SOCIOLOGÍA - ALAS, 30., 2015. San José, Costa Rica. Anais [...]. San José: ALAS, 2015.

FERRARI, Dilvan Luiz; MELLO, Márcio Antonio; TESTA, Vilson Marcos; SILVESTRO, Milton Luiz. Agricultores familiares, exclusão e desafios para inserção econômica na produção de leite em Santa Catarina. Informações Econômicas, São Paulo, v. 35, n. 1, p. 22-36, jan. 2005. Disponível em: www.iea.sp.gov.br/ ftpiea/ie/2005/tec2-0105.pdf. Acesso em: 18 jan. 2018.

FURTADO, Celso. Pequena introdução ao desenvolvimento: enfoque interdisciplinar. São Paulo: Nacional, 1980.

GIL, Antonio Carlos. Métodos e técnicas de pesquisa social. São Paulo: Atlas, 2010.

GONZÁLEZ REY, Fernando L. Pesquisa qualitativa em Psicologia: caminhos e desafios. São Paulo: Pioneira Thomson Learning, 2005.

INSTITUTO BRASILEIRO DE GEOGRAFIA E ESTATíSTICAS (IBGE). Pecuária. 2015. Disponível em: https:// sidra.ibge.gov.br/pesquisa/ppm/tabelas. Acesso em: 16 jan. 2018.

INSTITUTO BRASILEIRO DE GEOGRAFIA E ESTATíSTICAS (IBGE). Censo Agropecuário. 2006. Disponível em: https://sidra.ibge.gov.br/pesquisa/censo-agropecuario/censo-agropecuario-2006/segundaapuracao\#agricultura-familiar. Acesso em: 16 jan. 2018.

INSTITUTO NACIONAL DE COLONIZAÇÃO E REFORMA AGRÁRIA (INCRA). Classificação dos imóveis rurais. Brasília: INCRA, 2017. Disponível em: http://www.incra.gov.br/tamanho-propriedades-rurais. Acesso em: 16 jan. 2018. 
LAMARCHE, Hugues. Agriculture familiale II: du mythe à la realité. Paris: L'Harmattan, 1994.

LAMARCHE, Hugues. A agricultura familiar I: uma realidade multiforme. Campinas, SP: Editora da UNICAMP, 1993.

LUZ, Carlos Cesar Vieira da. Fatores que afetam a inovação tecnológica de sistemas produtivos de produtores familiares na cadeia produtiva leiteira do Distrito Federal. 2014. 191 f. Dissertação (Mestrado em Agronegócios) - Universidade de Brasília, Brasília, 2014. Disponível em: http://repositorio.unb.br/ handle/10482/16015. Acesso em: 20 abr. 2016.

MARASCHIN, Ângela de Faria. As relações entre produtores de leite e cooperativas: um estudo de caso na bacia leiteira de Santa Rosa-RS. 2004. 146 f. Orientador: Paulo Dabdab Waquil. Dissertação (Mestrado em Desenvolvimento Rural) - Universidade Federal do Rio Grande do Sul, Porto Alegre, 2004. Disponível em: http://www.lume.ufrgs.br/bitstream/handle/10183/6407/000485056. pdf?sequence=1. Acesso em: 20 abr. 2016.

MARTINS, José de Souza. O futuro da Sociologia Rural e sua contribuição para a qualidade de vida rural. Estudos Avançados, São Paulo, v. 15, n. 43, p. 31-6, set./dez. 2001. Disponível em: http://www.scielo.br/ scielo.php?script=sci_arttext\&pid=S0103-40142001000300004\&lng=pt\&nrm=iso. Acesso em: 5 abr. 2017.

MELLO, Márcio Antonio de. A trajetória da produção e transformação do leite no oeste catarinense e a busca de vias alternativas. 1998. 165 f. Dissertação (Mestrado em Agroecossistemas) - Universidade Federal de Santa Catarina, Florianópolis, 1998. Disponível em: http://repositorio.ufsc.br/xmlui/ handle/123456789/77904. Acesso em: 20 abr. 2016.

MORAES, Alexandra de. Produção leiteira e desenvolvimento regional: uma análise dos agentes da cadeia produtiva na Região Noroeste do Estado do Rio Grande do Sul. 2010. 165 f. Orientador: Milton Luiz Wittmann. Dissertação (Mestrado em Administração) - Universidade Federal de Santa Maria, Santa Maria, 2010. Disponível em: http://repositorio.ufsm.br/bitstream/handle/1/4564/MORAES\%2c\%20 ALEXANDRA\%20DE.pdf?sequence=1\&isAllowed=y. Acesso em: 20 abr. 2016.

RIQUINHO, Deise Lisboa; HENNINGTON, Élida Azevedo. Cultivo do tabaco no sul do Brasil: folha verde e outros agravos à saúde. Ciência \& Saúde Coletiva, Rio de Janeiro, v. 19, n. 12. p. 4797-808, 2014. Disponível em: http://www.scielo.br/scielo.php?script=sci_arttext\&pid=S1413-81232014001204797\&lng=en\&nrm =iso. Acesso em: 26 jan. 2018.

RODRIGUES, Renata Gonçalves. Atividade leiteria em unidades de produção familiar quanto a tipologia de produtores, na microregião de Erechim-RS. 2011. 115 f. Dissertação (Mestrado em Agronegócios) Universidade Federal do Rio Grande do Sul, Porto Alegre, 2011. Disponível em: http://www.lume.ufrgs. br/bitstream/handle/10183/60502/000861832.pdf?sequence=1. Acesso em: 20 abr. 2016.

SANTIAGO, Maria Helena Furtado. A sucessão em unidades produtoras de leite de base familiar na Zona da Mata Mineira. 2010. 123 f. Orientador: Ana Louise de Carvalho Fiúza. Dissertação (Mestrado em Extensão Rural) - Universidade Federal de Viçosa, Viçosa, MG, 2010. Disponível em: http://www.locus.ufv.br/bitstream/ handle/123456789/4146/texto\%20completo.pdf?sequence=1\&isAllowed=y. Acesso em: 20 abr. 2016.

SCHMITZ Aline Motter; SANTOS, Roselí Alves dos. A produção de leite na agricultura familiar do Sudoeste do Paraná e a participação das mulheres no processo produtivo. Terr@Plural, Ponta Grossa, PR, v. 7, n. 2, p. 339-55, jul./dez. 2013. Disponível em: www.revistas2.uepg.br/index.php/tp/article/viewFile/4543/3950. Acesso em: 31 jan. 2018.

SCHMITZ, Aline Motter. O trabalho das mulheres agricultoras familiares na atividade leiteira. 2014. 200 f. Orientador: Roselí Alves dos Santos. Dissertação (Mestrado em Geografia) - Universidade Estadual do 
Oeste do Paraná, Francisco Beltrão, 2014. Disponível em: http://tede.unioeste.br/bitstream/tede/1115/1/ ALINE\%20MOTTER.pdf. Acesso em: 20 abr. 2016.

SCHNEIDER, Sergio. Evolução e características da agricultura familiar no Brasil. Revista ALASRU - Análisis Latinoamericano del Medio Rural, Estado do México, n. 9, p. 21-52, out. 2014.

SEN, Amartya. Desenvolvimento com liberdade. São Paulo: Companhia das Letras, 2000.

VEIGA, José E. O desenvolvimento agrícola: uma visão histórica. São Paulo: Hucitec, 1991.

WANDERLEY, Maria de Nazareth Baudel. O mundo rural como um espaço de vida: reflexões sobre a propriedade da terra, agricultura familiar e ruralidade. Porto Alegre: Editora UFRGS, 2009.

WANDERLEY, Maria de Nazareth Baudel. Agricultura familiar e campesinato: rupturas e continuidade. Estudos Sociedade e Agricultura, Rio de Janeiro, v. 11, n. 2, p. 42-61, out. 2003. Disponível em: https:// revistaesa.com/ojs/index.php/esa/article/view/238. Acesso em: set. 2016.

WANDERLEY, Maria de Nazareth Baudel. Raízes históricas do campesinato brasileiro. In: TEDESCO, João Carlos (Org.). Agricultura familiar: realidades e perspectivas. 3. ed. Passo Fundo, RS: UPF, 2001. p. 21-55.

\section{Sobre os autores:}

Vandreça Vigarani Dorregão - Mestre em Desenvolvimento Socioeconômico pela Universidade do Extremo Sul Catarinense (UNESC). Bacharel em Psicologia pelo Centro Universitário Barriga Verde (Unibave). Coordenadora e professora nos Cursos de Psicologia e de Enfermagem do Unibave. E-mail: van.vigarani@gmail.com, Orcid: http://orcid.org/0000-0003-2802-9764

Giovana Ilka Jacinto Salvaro - Doutora em Ciências Humanas pela Universidade Federal de Santa Catarina (UFSC). Professora no Programas de Pós-Graduação em Desenvolvimento Socioeconômico e Direito e nos Cursos de Graduação em Psicologia, Direito e Ciências Econômicas da Universidade do Extremo Sul Catarinense (UNESC). E-mail: giovanailka@gmail.com, Orcid: http://orcid.org/0000-0002-8116-2209

Dimas de Oliveira Estevam - Doutor em Sociologia Política pela Universidade Federal de Santa Catarina (UFSC). Professor no Programa de Pós-Graduação em Desenvolvimento Socioeconômico e no Curso de Graduação em Ciências Econômicas da Universidade do Extremo Sul Catarinense (UNESC). E-mail: doe@unesc.net, Orcid: http://orcid.org/0000-0002-8116-2209 
